\section{The ability of Aliarcobacter butzleri strains isolated from foods of animal origin in Costa Rica to form biofilm}

\author{
Marco Chaves, ${ }^{1}$ \\ Daniel Vazquez-Valverde, ${ }^{1}$ \\ Heriberto Fernández-Jaramillo, ${ }^{2}$ \\ María Laura Arias-Echandi ${ }^{1}$ \\ ${ }^{1}$ Microbiology Faculty and Tropical \\ Diseases Research Center (CIET), \\ University of Costa Rica, San José, \\ Costa Rica; ${ }^{2}$ Institute of Clinical \\ Microbiology, Universidad Austral de \\ Chile, Los Ríos, Chile
}

\begin{abstract}
Aliarcobacter butzleri is a zoonotic emerging food and waterborne pathogen widely distributed in nature. It is present in food processing environments and can easily be spread through the food industry because of its ability to form biofilm. The aim of this work was to determine the ability of strains isolated in Costa Rica from different food matrixes of animal origin to form biofilm. Thirty-eight $A$. butzleri strains previously isolated and identified from animal origin products were analyzed using the method described by Stepmovic et al. (2000), in three culture broths, brain heart infusion broth, Boer broth and Houf broth.
\end{abstract}

Results showed that $67 \%$ of poultry origin strains, $62.5 \%$ of meat origin strains and just $8 \%$ of milk origin strains showed ability to form biofilm.

The findings of this study confirm the adherence ability of $A$. butzleri to form biofilm, a characteristic that can promote dispersion and cross contamination along food industry processing lines.

\section{Introduction}

Biofilm is defined as a thick layer of organisms, including bacteria, fungi and protists which aggregate in order to form a colony. This colony attaches to a surface with a slime layer and has a very important activity on the protection of microorganisms, promoting their growth and survival. Once formed, biofilms provide a protective surrounding environment, developing a complex structure that allows transfer of nutrients to bacteria and removal of waste products. Also, biofilm provides protection to bacteria in stressful environments, such as those in food industries and slaughterhouses. (Chmielewski and Frank, 2003)

The ability to form biofilm has been associated with bacterial virulence, colonization, environmental survival and even antibiotic resistance (Gaynor et al. 2007).

Furthermore, biofilms have been described as an important source of pathogenic bacteria (Parsek and Sigh, 2003). Indeed, biofilms have been been implicated in various infections, including many foodborne outbreaks have been linked to it (Dewangan and Bhadania, 2015), and Arcobacter is not an exception.

The ability of bacteria to adhere to and grow on abiotic surfaces is a critical issue for industries with suitable environments for biofilm formation (Girbau et al. 2017) including food industries, where organic and inorganic residues easily accumulate. Product contact with these biofilms can lead to health problems if contaminated by pathogenic bacteria (Mafu et al. 2011).

Aliarcobacter are Gram negative rods taxonomically included in the family Campylobacteriaceae (Silha et al. 2019). This genus comprises several species, some of them considered as pathogenic for human beings.

Aliarcobacter butzleri is a zoonotic emerging food and waterborne pathogen widely distributed in nature, frequently isolated from water, animals, and foods of animal (Girbau et al., 2017) and vegetable origin (Mottola et al., 2016; Gonzalez et al., 2019; Girbau et al., 2017). It has been commonly isolated from food processing and handling facilities (Ferreria et al., 2013). Also, it is present in food processing environments and can be persistent in equipment associated with the food industry (Giacometti et al., 2015). This persistence has been associated with biofilm formation by several researchers (Ferreira et al., 2013). Adherence to different surfaces can favour cross contamination and bacterial spread onto food.

Transmission of this bacterium is supported by various inherent bacterial properties, including its ability to form biofilm under different environmental conditions. It is known that this bacterium can form biofilm on stainless steel, copper and plastic surfaces, materials commonly used on food industry (Assanta et al., 2002).

Arcobacter spp. can be the cause of gastroenteritis in human beings, especially A. butzleri, which has been included in the list of dangerous microorganisms for human health by the International Commission of Microbiological Specifications for Food (ICMSF) (Banting and Figueras, 2017).

Considering the increasing risk this bacterium represents for public health and the
Correspondence: María Laura Arias-Echandi, Faculty of Microbiology, University of Costa Rica, San José, Costa Rica.

E-mail: maria.ariasechandi@ucr.ac.cr

Key words: Aliarcobacter butzleri, biofilm, food of animal origin.

Acknowledgements: The authors thank Dr. Martin Skiroww, former Consultant Medical Microbiologist, Worcester Royal Hospital, UK, for his advice and syntactic revision of the English language in which this work was written.

Conflict of interest: The authors declare no conflict of interest.

Contributions: The authors contributed equally.

Funding: None

Ethics approval: This research was conducted in accordance with all relevant guidelines and procedures.

Received for publication: 11 April 2020

Revision received: 5 September 2020

Accepted for publication: 22 March 2021.

This work is licensed under a Creative Commons Attribution-NonCommercial 4.0 International License (CC BY-NC 4.0).

(C) Copyright: the Author(s), 2021

Licensee PAGEPress, Italy

Italian Journal of Food Safety 2021; $10: 9020$

doi:10.4081/ijfs.2021.9020

fact that it can easily be spread through the food industry, it is important to analyze the ability of biofilm formation of strains isolated from different foods of animal origin, in this case in Costa Rica. The aim of this study was to determine the ability of $28 \mathrm{~A}$. butzleri isolates recovered from animal origin products from Costa Rica to form biofilm.

\section{Materials and methods}

\section{Bacterial strains}

Thirty-eight $A$. butzleri strains were studied. These were previously isolated and identified from animal origin products, including poultry meat $(\mathrm{n}=18)$, bovine meat $(\mathrm{n}=8)$ and milk $(\mathrm{n}=12)$. Poultry strains were isolated from chicken viscera and carcasses (Garcia et al., 2013; Fallas et al., 2014). Bovine meat samples were isolated from minced meat (Córdoba et al., 2017) and unpasteurized milk samples from the Northern region of the country. These 
strains were kept frozen at $-70^{\circ} \mathrm{C}$ at the Food Microbiology Laboratory, University of Costa Rica.

Before analysis, all strains were transferred from stock cultures to tripticase soy broth and incubated aerobically at $30^{\circ} \mathrm{C}$ for $24 \mathrm{~h}$. After incubation, each strain was adjusted to a final optical density (OD) 600 $\mathrm{nm}$ of 0.1 using sterile peptonized water $0.1 \%$.

\section{Biofilm formation assay and biofilm quantification}

The ability of $A$. butzleri strains to form biofilms was determined using the method described by Stepmovic et al. (2000) in three different opportunities. Briefly, 96well flatbottomed plastic tissue culture plates with lid (Thermo Scientific) were inoculated with three different culture broths, brain heart infusion broth (row 1), Boer broth (row 2) and Houf broth (row 3). Each row of media was inoculated, in triplicate, with 20 ul of the inoculum previously prepared. The last two wells of each row were used as negative controls containing only broth. Each plate was incubated for $72 \mathrm{~h}$ at $25^{\circ} \mathrm{C}$ under aerobic conditions. After this period, the content of each well was aspirated and washed three times with 250ul sterile physiological saline solution. Plates were vigorously shaken in order to remove all non-adherent bacteria. The remaining attached bacteria were fixed with $300 \mathrm{ul}$ methanol and after $15 \mathrm{~min}$, plates were emptied and left to dry and stained for 5 min with crystal violet $0.2 \% \mathrm{v} / \mathrm{v}$ in $20 \%$ ethanol (300 ul/well) for $5 \mathrm{~min}$. After this period, plates were rinsed off with tap water for three times in order to eliminate any excess of stain and then air dried. The dye that had adhered to biofilm was suspended in $250 \mathrm{uL} /$ well glacial acetic acid $(33 \% \mathrm{v} / \mathrm{v})$. The optical density (OD) of each well was measured at $570 \mathrm{~nm}$ using an automated Epock Biotek microplate reader. Each measurement was carried out in triplicate

Adherence capability was graaded into four different categories: non-adherent (-), weakly adherent $(+)$, moderately adherent $(++)$ and strongly adherent $(+++)$ based on the OD obtained as described by Stepanovic et al (2000)

The cut off OD (COD) was defined as three standard deviations above the mean OD of the negative control. If the OD obtained was under this value, the strain was classified as a non-producer. If the OD was greater than cut off and less than 2 COD, the strain was classified as weakly adherent. Moderately adherent strainswere those strains that presented an OD smaller than $4 \mathrm{COD}$, and strong biofilm produceing strains were those that presented an OD greater than $4 \mathrm{COD}$.

The results were statistically evaluated with SPSS 19.0 statistical package software. Statistical significance was determined by chi-square-one-way analysis of variance (ANOVA). Results were considered as significant at $\mathrm{p}<0.05$.

\section{Results}

Results obtained showed that $67 \%$ of poultry meat strains, $62.5 \%$ of bovine meat strains and just $8 \%$ of milk strains showed an ability to form biofilm $(\mathrm{p}<0.05)$. The grading of this adherece is shown on Table 1 .

Brain heart infusion broth was the medium that promoted most frequently the formation of biofilm compared with Boer and Houf broths, in which most of the strains evaluated promoted weak or noadherent properties.

In brain heart infusion broth $67 \%$ of poultry strains showed adherence, and 7/18 of these were classified as strong adherents. Similar results were shown by meat origin strains, of which $62 \%$ showed some kind of adhesion, and $3 / 8$ were strong adherents.

Only one of the strains isolated from milk showed adhesion and this was in Boer broth.

\section{Discussion and conclusions}

The persistence of microorganisms in food processing environments, including potentially pathogenic bacteria is a current growing public health problem worldwide.

A. butzleri transmission could possibly be enhanced by its ability to adhere to abiotic surfaces. Bacterial ability to adhere to and grow on abiotic surfaces is a critical issue for industries that provide a suitable environment for biofilm formation (Abdahha et al., 2014).

In this study, a total of $17 / 38$ strains $(45 \%)$ showed ability to form biofilms. These results are lower than the ones reported by Ferreira et at. (2014) and Kjeldgaard et al. (2009) who report a $100 \%$ adhesion on polystyrene surfaces, but greater than the $19.7 \%$ reported by Ferreira (2013) from strains isolated from poultry and the environment in a Portuguese slaughterhouse.

Our results showed that most of the $A$. butzleri isolates coming from poultry and bovine meat samples showed adherent characteristics, varying from weak to strong. Only $33 \%$ of poultry meat samples and $38 \%$ of bovine meat samples did not show any in vitro adherence.

For poultry meat samples, $39 \%$ were strongly adherent, a result that contrasts with the ones reported by Ferreira et al. (2013), where only one isolate was strongly adherent (Ferreira et al., 2013). The $28 \%$ of the strains isolated from bovine meat also were also characterized as strongly adherent.

The ability to form biofilm can vary greatly among strains of the same species depending on extrinsic factors such as nutrient availability, environmental conditions and surface properties (Girbau et al., 2017). In this respect, it is important to point out that even weakly adherent isolates can produce biofilm and therefore be difficult to eliminate from the food chain (Srey et al., 2013). Also, a weakly adherent bacterium may become strongly adherent depending

Table 1. The ability of Aliarcobacter butzleri strains isolated from three animal sources to foirm biofilm in different culture broths.

\begin{tabular}{|c|c|c|c|c|c|}
\hline & Culture broth & $\begin{array}{c}\text { Non-adherent, } \\
\text { n (\%) }\end{array}$ & $\begin{array}{c}\text { Weakley adherent, } \\
\text { n (\%) }\end{array}$ & $\begin{array}{c}\text { Moderately adherent, } \\
\text { n (\%) }\end{array}$ & $\begin{array}{c}\text { Strongly adherent, } \\
\text { n (\%) }\end{array}$ \\
\hline Poultry meat $n=18$ & $\begin{array}{l}\text { Brain heart infusion broth } \\
\text { Boer broth } \\
\text { Houf broth }\end{array}$ & $\begin{array}{c}6(33) \\
18(100) \\
17(94)\end{array}$ & $\begin{array}{c}3(17) \\
0 \\
1(6)\end{array}$ & $\begin{array}{c}2(11) \\
0 \\
0\end{array}$ & $\begin{array}{c}7(39) \\
0 \\
0\end{array}$ \\
\hline Bovine meat $n=8$ & $\begin{array}{l}\text { Brain heart infusion broth } \\
\text { Boer broth } \\
\text { Houf broth }\end{array}$ & $\begin{array}{l}3(38) \\
8(100) \\
8(100)\end{array}$ & $\begin{array}{c}1(12) \\
0 \\
0\end{array}$ & $\begin{array}{c}1(12) \\
0 \\
0\end{array}$ & $\begin{array}{c}3(38) \\
0 \\
0\end{array}$ \\
\hline Milk $n=12$ & $\begin{array}{l}\text { Brain heart infusion broth } \\
\text { Boer broth } \\
\text { Houf broth }\end{array}$ & $\begin{array}{l}12(100) \\
11(92) \\
12(100)\end{array}$ & $\begin{array}{c}0 \\
1(8) \\
0\end{array}$ & $\begin{array}{l}0 \\
0 \\
0\end{array}$ & $\begin{array}{l}0 \\
0 \\
0\end{array}$ \\
\hline
\end{tabular}


on environmental conditions, as demonstrated in this study. A. butzleri strains growing in a rich medium such as brain heart infusion broth showed stronger adherent capacities than when they were cultured in selective media, such as Boer and Houf media.

Nutrient rich media do not support optimal biofilm formation, but nutritionally poor environments do promote biofilm formation as described by Reeser et al. 2007. Nevertheless, the presence of inhibitory substances in media, as those present in Houf and Boer media, decrease its formation.

Several researchers have described a high prevalence of Arcobacter spp on chicken carcasses and on slaughterhouse surfaces, but the isolation from intestinal content is very low or null. (Hanning et al., 2008, Ferreira et al., 2013). Biofilm formation could be the explanation for these discrepancies. This bacterium may reside and proliferate in the slaughterhouse environment and contaminate meat production even under chilled conditions (Ferreira et al., 2013).

A. butzleri has been isolated from cow's milk with lower prevalence than that found in poultry and meat. Pianta et al, isolated just one strain of this bacterium in 188 milk samples from dairy cows (Piant et al., 2007).

The A. butzleri strains isolated from milk analyzed in this work showed a very small ability to form biofilm, but few samples were analyzed and further research needs to be done in order to understand this behavior.

In this study biofilm formation from strains isolated from milk was low, just one of 12 strains showed a weak ability. Similar results were reported by Girbau et al. (2017) where $3 / 15$ milk isolates showed the ability to form biofilm. Chi square test showed no relationship between the adhesion ability of the isolates and the source ( $p>0,05$ ), except for milk, but only a small number of isolates were analyzed.

Stainless steel is a material widely used in the food industry, including poultry, meat and milk processing, because it has some of the most suitable properties for materials used for food equipment (Dewangan and Bhadania, 2015). Few studies have been conducted on the biofilm formation of $A$. butzleri on stainless steel surfaces. Asanta et al. (2002) and Kjelgaard et al. (2009) demonstrated the adhesion capability of this bacterium to this material. Further research is planned for assessing the ability of $A$. butzleri to form biofilm on the materials present in food lines, particularly stainless steel.

The findings of this study confirm the feared ability of $A$. butzleri to produce biofilm, a characteristic that can cause dispersion and cross contamination along food industry processing lines. Studies on biofilm formation are still scarce, further research is planned to assess the importance of biofilm formation as a virulence determinant and the development of natural or synthetic products that could inhibit it.

Data obtained in this work contributes to the understanding of the survival, persistence and dissemination mechanisms of this bacterium and the potential risk it represents for human public health.

\section{References}

Abdahha M, Benolil C, Drider D, Dhulster P, Chihib N, 2014. Biofilm formation and persistence on abiotic surfaces in the context of food and medical environments. Arch Microbiol 196: 453-72.

Assanta M, Roy D, Lenay M, Montpetit D, 2002. Attachment of Arcobacter butzleri, a new waterborne pathogen, to water distribution pipe surfaces. J Food Prot 65: 1240-7.

Banting $\mathrm{G}$ and Figueras MJ. Arcobacter. In: J.B. Rose and B. Jiménez-Cisneros, (eds) Global Water Pathogens Project. Michigan State University, E. Lansing, MI, UNESCO; 2017.

Chmielewski R, Frank JF, 2003. Biofilm formation and control in food processing facilities. Compr Rev Food Sci F 2: 22-32.

Córdoba-Calderón O, Redondo-Solano M, Castro-Arias E, Arias-Echandi ML, 2017. Arcobacter isolation from minced beef samples in Costa Rica. J Food Prot 80: 775-7.

Dewangan AK, Bhadania AG, 2015. Stainless steel for dairy and food industry: a review. J Mater Sci Eng 4: 1000191.

Fallas-Padilla K, Rodríguez-Rodríguez CE, Fernández-Jaramillo $\mathrm{H}$, Arias-Echandi ML, 2014. Arcobacter: comparison of isolation methods, diversity and potential pathogenic factors in commercially retailed chicken breast meat from Costa Rica. J Food Prot 77: 880-4.

Ferreira S, Fraqueza M, Queiroz J, Domingues F, Oleastro M, 2013. Genetic diversity, antibiotic resistance and biofilm forming ability of Arcobacter butzleri isolated from poultry and environment from a Portuguese slaughterhouse. Int $\mathrm{J}$ Food Microbiol 162: 82-8.

Ferreira S, Queiroz J, Oleastro M, Domingues F, 2014. Genotypic and phenotypic features of Arcobacter butz- leri pathogenicity. Micro Pathog 76: 19. 25.

Garcia E, Fernández-Jaramillo H, ChavesUlate C, Arias-Echandi ML, 2013. Isolation and identification of zoonotic species of genus Arcobacter from chicken viscera obtained from retail distributors of the metropolitan area of San José, Costa Rica. J Food Prot 76: 87988.

Gaynor E, Candon H, Allna B, Fraley C, 2007. Polyphosphate kinase 1 is a pathogenesis determinant of Campylobacter jejuni. J. Bacteriol. 189: 8099-108.

Giacometti F, Lucchi A, Di Francesco A, Delogu M, Grilli E, Serraino I, 2015. Arcobacter butzleri, Arcobacter cryaerophilus and Arcobacter skirrowii circulating in a dairy farm and sources of milk contamination. Appl Environ Microbiol 81: 5055-63.

Girbau C, Martinez I, Muruaga G, Carmona S, Alonso R, Fernandez A, 2017. Study of biofilm formation ability of foodborne Arcobacter butzleri under different conditions. J Food Prot 80: 758-62.

González A, Bayas I, Ferrús M, 2017. Isolation, molecular identification and quinolone-susceptibility testing of Arcobacter spp. isolated from fresh vegetables in Spain. Food Microb 65: 279-83.

Hannning I, Jarquin R, Slavik M, 2008. Campylobacter jejuni as secondary colonizer of poultry biofilms. J Appl Microbiol 105: 1199-208.

Kjeldgaard J, Jorgensen K, Ingmer H, 2009. Growth and survival at chiller temperatures of Arcobacter butzleri. Int J Food Microbiol 131: 256-9.

Mafu AA, Plumety C, Deschenes L, Goulet J, 2011. Adhesion and pathogenic bacteria to food contact surfaces: influence of $\mathrm{pH}$ of culture. Int J Microbiol 2011: 972494.

Mottla, A, Bonerba E, Bozzo G, Marchetti P, Vitale G, Colao V, Terio V, Tantillo G, Figueras MJ, Pinto A, 2016. Occurrence of emerging food borne pathogenic Arcobacter spp. Isolated from pre-cut (ready to eat) vegetables. Int J Food Microbiol 7: 33-7.

Parsek MR, Singh PK, 2003. Bacterial biofilms: an emerging link to disease pathogenesis. Ann Rev Microbiol 57: 677-701.

Pianta C, Thompsen D, Hepp D, de Oliveira S, 2007. Isolation of Arcobacter spp from the milk of dairy cows in Brazil. 2007. Cienc. Rural 37. Online version ISSN 1678-4596.

Reeser R, Medler R, Billington S, Jost H, Joens L, 2007. Characterization of 
Campylobacter jejuni biofilms under defined growth conditions. Appl Environ Microbiol 73: 1908-913.

Silha D, Moravkova, K, Skodova G, Vytrasova J, 2019. Viability and biofilm formation of Arcobacter spp. at various processing temperatures. JFNR 58: 308-13.

Srey S, Jahid IK, Ha S, 2013. Biofilm formation in food industries: a food safety concern. Food Control 31: 572-85.

Stepanovic S, Vukovic D, Dakié I, Savié B,
Svabic-Vlahovié S, 2000. A modified microtiter-plate test for quantification of staphylococcal biofilm formation. J Microbiol Methods 40: 175-9. 